\title{
A TRANSMIGRAÇÃO DOS GUARANIS PARA A ALDEIA DE NOSSA SENHORA DOS ANJOS
}

\author{
Moacyr Flores
}

\section{1 - O ESPAÇO MISSIONEIRO}

As missões jesuíticas do Paraguai ocuparam um espaço que se direcionava em 3 dimensões: geográfica, social e temporal.

Só fixando o índio numa área seria possível desenvolver a alteração da ordem existente entre os guaranis, dimensionando-a nos valores do cristianismo.

A dimensão geográfica era de interesse da Coroa da Espanha, empenhada, no século XVII, em conquistar e colonizar a região. A colonização espanhola realizou-se através de pueblos, ou povoados, contando com 30 homens capazes de pegar em armas e de instalarem um cabildo para a administração e distribuição de justiça. Como havia failta de homens brancos na América, a Espanha determinou a fundação de pueblos com índios, com o objetivo de ocupar terras e deter o avanço português, este muito mais rápido porque se fazia através de doação de sesmarias.

$\mathrm{Na}$ época, considerava-se civilizado quem morava na cívitas, isto é na área urbana, sendo considerado bárbaro, atrasado, quem morasse na selva, portanto um selvagem, antítese do civilizado.

A dimensão humana foi dada pelo jesuíta, que organizou o espaço social missioneiro garantindo a evangelização, a subsistência e a liberdade do índio. As reduções tornaram-se autosuficientes pela pecuária e produção agrícola, que também garantiram a fixação dos índios no espaço reducional.

Os missionários jesuítas conservaram a língua guarani como meio de melhor se comunicarem com os nativos, mantendo assim a continuidade cultural relativa, pois substituíram a religião e modificaram o uso do tempo indígena.

O índio é prático, ocupa o tempo presente para viver, não se preocupa com o futuro, não tem idéia de acúmulo de riquezas. Os missionários, partindo do princípio que a ociosidade é mãe de todos os vícios regularam o tempo para manter os índios ocupados com trabalho, orações, missas, cantos, teatro religioso e lazer orientado. 
O tratado de Madrid, de 1750, rompeu com o espaço organizado das reduções jesuíticas, forçando os índios a abandonarem suas terras, colocando-os em serviço militar até marginalizá-los como bêbados e preguiçosos.

\section{2 - A TRANSMIGRAÇÃO}

O artigo 160 do Tratado de Madrid estipulava a transmigração dos Sete Povos para a outra margem do rio Uruguai e a saída dos jesuítas, como medida de segurança para evitar futuras rebeliões contra os colonos portugueses que deveriam se estabelecer nestas terras.

No século XVIII mudara a política internacional, agora as fronteiras eram estabelecidas através de tratados e não unicamente por povoamento. Faltava mão-de-obra nas colônias espanholas, principalmente nos ervais da serra de Maracaju. As reduções jesuíticas dos Sete Povos, com uma população de mais de 30 mil índios, era um novo estoque de mão-de-obra especializada, pois todo o índio conhecia agricultura e tinha mais de uma profissão. Assim, não havia mais interesse para a Espanha na continuidade das reduções, pois as estâncias espanholas já avançavam em direção as cabeceiras do rio Negro, onde começavam os campos de criação dos missioneiros.

O domínio de ambas as margens do rio da Prata era mais importante que a manutenção dos Sete Povos, considerada pelas autoridades espanholas como simples aldeias indígenas.

A execução da transmigração encontrou forte oposição dos índios, tanto da margem esquerda, como os da margem direita do rio Uruguai, este alegando que não havia mais terras disponíveis para novos povoados, lavouras e estâncias.

Os missioneiros usaram de todos os meios para evitar a transmigração. Havia confusões nas ordens transmitidas. Os habitantes de S. Miguel e S. Nicolau se recusaram preparar algodão, erva-mate, lã e gado para o transporte. Os índios de $\mathrm{S}$. Borja concordaram com a mudança, mas com malícias protelaram ao máximo a viagem. Os guaranis de $\mathrm{S}$. Luís se recusaram a se fixar em terras de charruas, que receberam fumo, erva-mate e ponchos para se acalmarem e não atacarem os missioneiros. Os de S. João iniciaram a mudança, mas fugiram em grupos durante o percurso até a margem do rio Uruguai. Os de S. Lourenço espalharam o boato de que os padres iriam vendê-los em Buenos Aires aos bandeirantes paulistas. Em Santo Ângelo os indios deixaram de obedecer ao cura. ${ }^{1}$

A tentativa de execução do Tratado de Madrid provocou o desiquilíbrio no espaço missioneiro e gerou a guerra guaranítica, que trouxe a destruição e a fome para os Sete Povos, porque os índios deixaram de semear e de plantar, 
suas estâncias foram pilhadas pelos soldados portugueses, espanhóis e índios charruas.

Rompido o espaço fechado da redução, os guaranis passaram a percorrer a campanha e suas estâncias, tentando formar um novo espaço semelhante ao que ocupavam antes da organização missioneira. A volta à vida primitiva não era mais possível, os espaços geográficos estavam sendo ocupados rapidamente com estâncias espanholas e portuguesas. Não havia mais lugar para uma aldeia indígena organizada como era antes da chegada dos europeus. A maioria dos missioneiros permaneceram nas reduções, prontos para enfrentarem os invasores.

Portugal e Espanha mandaram seus exércitos subjugar os índios, que impediam o prosseguimento da démarcação das fronteiras. O massacre de Caiboaté, em 10.2.1756, onde morreram mais de 1.500 índios e só 3 europeus, demonstra que a resistência desesperada dos guaranis não contava com preparo militar suficiente para enfrentar os invasores bem armados e treinados. Os ataques de guerrilhas foram insuficientes para deter o avanço dos lusos e espanhóis, que entraram a 16 de maio em S. Miguel. Os portugueses estabeleceram acampamen to em Santo Ângelo e os espanhóis em S. João. ${ }^{2}$

Ao tomarem conta dos Sete Povos, portugueses e espanhóis romperam também com a dimensão social.

Juan de Escandón escreveu em 1760 que os índios cheios de pavor fugiam para os matos, debandavam desesperados pelos campos, ninguém pensava em outra coisa senão salvar suas vidas. Das 30.600 almas restavam apenas 15.000 nos Sete Povos, com esperança que seriam perdoados, seguiam com os padres e se apresentavam aos generais vencedores, menos os de $\mathrm{S}$. Miguel que continuavam refugiados nos matos. Os espanhóis agiram com violência, confiscando tudo, principalmente o que se encontrava nos armazéns, desrespeitando os padres. ${ }^{3}$

Os espanhóis usaram de força para levar os missioneiros para a outra margem do rio Uruguai, auxiliados pelo padre Balda conseguiram juntar pouco mais de 300 famílias, que logo repassaram o rio de regresso às terras de $\mathrm{S}$. Miguel. Apesar da inclemência do inverno, os miguelistas vagueavam pelos campos, até que reuniram no lugar chamado de Apicazuró, que significa pombal, na Serra dos Tapes, em terras de sua estância. ${ }^{4}$

Os soldados portugueses, instruídos por Gomes Freire de Andrada, trataram bem os guaranis desde o acampamento em Rio Pardo, em 1754, quando funcionava um posto de troca diária entre índios e soldados.

Gomes Freire renunciou parte dos despojos que deveriam tocar aos portugueses em favor dos índios. Os lusos visitavam os índios em suas casas, dando presentes, pagando tudo que recebiam e expressavam o desejo de casar com as índias. Os padres espanhóis não permitiam estes casamentos porque os 
portugueses queriam voltar para o território do Rio Grande, levando a muther índia e seus parentes. ${ }^{5}$

Os espanhóis se apoderaram de todos os bens dos missioneiros, inclusive daqueles que os lusos deixaram aos índios. Os espanhóis trataram os índios com altivez, desprezo e sem compaixão por suas desgraças. Em 1757, o procurador das Missões informou que os Sete Povos não podiam pagar tributos por causa de sua penosa transmigração e porque Don Joseph de Andonaegui, comissário espanhol da demarcação do tratado, ordenou em 1753 o confisco do gado existente nas estâncias dos Sete Povos, para alimentar os exércitos espanhol e português, deixando os índios na miséria. ${ }^{6}$

Em sua simplicidade os índios se convenceram que os castelhanos só queriam mudá-los de seus povoados. A fama de bom tratamento dispensado pelos lusos, fez com que os missioneiros de outros povoados seguissem para Santo Ângelo, de onde partiam em grupos para Rio Pardo.

Em fins de 1757, Don Pedro de Ceballos, novo governador espanhol, chegou às missões e mudou o relacionamento com os índios, recebendo homenagens e obediência por parte dos missioneiros e padres. Depois de dois anos, os espanhóis conseguiram mudar cerca de 12 mil índios para os povoados entre os rios Uruguai e Paraná.

Quando Don Pedro de Ceballos tentou efetuar a troca dos Sete Povos pela Colônia do Santíssimo Sacramento, o general Gomes Freire de Andrada alegou que não havia segurança para trazer 300 famílias de açorianos, que estavam em diversos pontos do Rio Grande, para as Missões, enquanto existissem índios e jesuítas. Gomes Freire retirou-se para Rio Pardo, levando 700 famílias guaranis, além de vacas e cavalos.

O comandante espanhol conseguiu buscar cerca de 200 em Rio Pardo.

Com a desorganização do espaço missioneiro, os campos passaram a ser percorridos por guaranis, charruas, minuanos, desertores e vagabundos.

Como não foi efetuada a troca dos Sete Povos pela Colônia do Santíssimo Sacramento, os inacianos tentaram reconstruir o espaço missioneiro, até serem expulsos em 1768.

\section{3 - ORGANIZAÇÃO DE NOVO ESPAÇO INDÍGENA}

Durante a guerra guaranítica, em 1751, famílias de guaranis buscaram abrigo junto à vila de Rio Grande. Os moradores ficaram com receio dos índios junto à vila e pressionaram as autoridades para mudá-los para a aldeia de Estreito, com assistência de 2 padres.

Em 1758, os índios guaranis foram arranchados na aldeia de S. Nicolau, junto a Rio Pardo e na aldeia de S. Nicolau na outra margem do rio Jacuí, 
dando origem à vila de Cachoeira do Sul. Na mesma época criaram outra aldeia na Guarda Velha de Viamão, hoje Santo Antonio da Patrulha.

Em 1762 eclodiu nova guerra entre Portugal e Espanha. D. Pedro de Ceballos conquistou a Colônia do Santíssimo Sacramento e invadiu a vila de Rio Grande, limitando o espaço português aos Campos de Viamão e à margem esquerda do rio Jacuí.

Tentando conquistar este espaço, o capitão Don Joseph Gomez reuniu índios a cavalo para atacar Rio Pardo. Em janeiro de 1763, Rafael Pinto Bandeira atacou o acampamento dos índios dos Sete Povos e tirou-lhes a cavalhada, frustrando o plano de ataque. ${ }^{7}$

Receando que os guaranis aldeados em S. Nicolau de Rio Pardo se colocassem ao lado dos espanhóis, o governador José Custódio de Sá e Faria ordenou a mudança de famílias guaranis para os Campos de Viamão.

Em 1762 foram transferidos para a nova Aldeia dos Anjos, junto ao rio Gravatai, conforme registros em livros de batismos da igreja de Viamão, pesquisados por monsenhor Ruben Neis. ${ }^{8}$

Não encontramos documentos sobre a maneira como transferiram os índios para junto do rio Gravataí, mas no Livro de Matrículas dos índios de Nossa Senhora dos Anjos, com data inicial de 20.6.1768, encontramos vários dados que nos permitem reconstituir o espaço em suas dimensões geográficas, sociais e temporal.

A invasão espanhola provocou uma redivisão do espaço, porque constantemente famílias de refugiados chegavam aos Campos de Viamão, fugindo da Colônia do Santíssimo Sacramento, do Chuí e da vila de Rio Grande. Desde 1752 que famílias açorianas em Viamão, Porto do Dorneles, Taquari, Rio Pardo aguardavam suas terras prometidas. Os recém chegados queriam terras provocando medidas ordenadoras do governador José Custódio de Sá e Faria, que em edital de 8.9.1764 ordenava a medição e demarcação das terras.

$\mathrm{O}$ edital de 1765 alertava sobre o prejuízo dos moradores com a província infestada de ladrões fascinorosos, matadores, desertores e índios dispersos em toda parte, obrigando a militares, estancieiros e moradores a entregar os índios na Aldeia dos Anjos, ao capitão Antônio Pinto Carneiro.

A terra destinada aos índios junto ao rio Gravataí foram cobiçadas pelos brancos, que sugeriram a mudança dos guaranis para a enseada de Garoupas, onde poderiam viver de farinha e peixe.

O objetivo da transmigração de índios para a Aldeia dos Anjos e Aldeia de São João Batista, no sopé da serra, era para afastar os índios guaranis dos espanhóis, que sempre os utilizaram como soldados em suas milícias e também enfraquecer o lado espanhol, levando parte da população que, no dizer de Juan Escandon, atingiu mais de 10.000 índios. 
O espaço geográfico da Aldeia dos Anjos iniciou em 1762, com 1/2 légua da margem do rio Gravataí, parte tirada da estância de João Lourenço Veloso. Não houve necessidade de desapropriação, porque de acordo com a lei de concessão de sesmaria, $1 / 2$ légua junto ao rio navegável pertencia a El Rei. Não havia preocupação de dar continuidade à Aldeia, os índios eram alimentados com o gado requisitado das estâncias vizinhas, os quais o governo não pagava, e com animais roubados pelos índios. Em troca da ração de carne, os índios serviam como mão-de-obra nas estâncias, na condução de gado, na construção de fortificações, de quartéis e arsenal.

$\mathrm{O}$ indígena era considerado como preguiçoso, bêbado e ladrão de gado, sem condições de tirar seu sustento da própria terra. As fugas constantes diminuiam o total demográfico. Não havia interesse de manter para sempre os índios nestas terras, cobiçadas por brancos. Era apenas uma fixação provisória, enquanto durasse a guerra com os espanhóis.

A mudança ocorreu somente durante o governo de José Marcelino de Figueiredo, de 1769 a 1780 . O espaço geográfico foi ampliado e ordenado em busca da auto-suficiência dos índios. O edital de 1769 determinava recolher a S. Nicolau de Rio Pardo e a Aldeia dos Anjos os índios vagos. No mesmo ano é regulamentada a jornada de trabalho dos índios, contratados por estancieiros e charqueadores, proibindo a pena de açoites.

Em 1770 amplia-se o espaço geográfico com a compra do restante da estância que agora pertencia a Francisco José da Costa, num total de légua e meia de comprimento, por duas de largura, para aumentar as roças dos índios até o morro do Itacolomi.

Foi nomeado um administrador das lavouras para plantar trigo, mandioca, algodão e fumo. Nos quintas das casas plantavam laranjeiras e pessegueiros. $\mathrm{O}$ administrador dividiu os índios em grupos para trabalharem na terra da comunidade, sem prejuízo das roças particulares.

Em 1771, José Marcelino nomeou capataz e deu instruções para organizar a Estância dos Povos, localizada no rincão de Cristóvão Pereira, entre a Laguna dos Patos e o oceano. O gado foi retirado das estâncias dos Sete Povos com a alegação que pertenciam aos índios que fugiram para o lado dos portugueses. Quarenta peões indígenas cuidavam da estância tropeandc o gado até o açougue da Aldeia, onde era repartida a ração de carne. A estância fornecia queijo, manteiga, graxa, sebo, velas e couro.

A Aldeia recebeu ruas, com alinhamento dos ranchos, a matriz foi erguida em 1774. No ano de 1776 organizou-se a irmandade do Santíssimo Sacramento, que também recebeu índios como irmãos. O cemitério, inaugurado em 1777 , pertencia à Irmandade de S. Miguel e Almas.

A ordem foi mantida pelas Milícias Guaranis, com uma companhia a pé e outra a cavalo. Os faltosos eram punidos no tronco ou na prisão. 
A Caixa dos Indios, mantida pela venda de carne, do couro e de produtos agrícolas, pagava os cirurgiões, leito no hospital e os remédios da botica.

Os índios foram obrigados a aprender português e a doutrina cristã para que esquecessem suas superstições. A Escola de Meninos, criada em 1770, chegou a ter 60 crianças, formando 4 rapazes que estudaram no Rio de Janeiro, onde 2 se tornaram padres. A Escola foi transformada em internato em 1776. No ano de 1777 criaram o Recolhimento das Meninas, onde se ensinava a falar em português, tecer, fiar e costurar. Apesar de serem prendadas, não conseguiram casamento com os brancos por falta de dote. No Livro de Matrículas dos Indios, num total de 2.619 nomes, só encontramos uma índia que casou com pardo e três que casaram com brancos, até o ano de 1780 .

A administração geral da Aldeia ficava sob as ordens de um comandante militar, auxiliado pelos caciques que comandavam as companhias de milícia guarani. O primeiro comandante foi o capitão Antônio Pinto Carneiro.

O novo governador, Sebastião da Veiga Cabral, em 14.1.1781, instruiu o novo comandante da Aldeia, Antônio José Machado, previnindo que a população estava dividida em parcialidades por causa dos caprichos, ódios e vinganças de seus moradores, composta principalmente por índios bêbados, fujões e preguiçosos. As poucas famílias brancas eram honradas e pouco trabalho dariam ao comandante.

Sebastião da Veiga Cabral reclamava que os índios ainda não tiravam da terra o seu sustento e que as índias iam à rua vestidas com camisa de algodão, pouco faltando para chegar ao chão, devido à extrema pobreza. Sugeria que elas usassem colete e saia colorida com ervas. Também determinava que mulheres não andassem com os cabelos soltos, parecendo mais com animais do que com gente racional e pertencentes à sociedade civil.

Nos Sete Povos os missionários romperam com a religião indígena, substituindo-a pelo catolocismo. Veiga Cabral informa que em 1781 os índios da Aldeia não sabiam mais rezar, eram indiferentes em cumprir os preceitos da Quaresma, ouvir missa e doutrina cristã.

Com a fundação da Real Feitoria do Linho Cânhamo, no Faxinal do Courita, em 1788 levaram 13 indios para trabalhar com seus bois e carretas a 200 réis por dia. Em dezembro mais 20 índios, a 100 réis por dia, derrubaram um trecho de mato para a sementeira.

Abandonados, marginalizados, novamente os índios guaranis tiveram seu espaço destruído, porque não havia mais interesse em conservá-los no lugar, mesmo com a ampliação do território rio-grandense com conquista de terras ao sul do rio Jacuí, a partir de 1777. A demografia indígena manteve-se estável durante o governo de José Marcelino, mas caiu rapidamente com as fugas da Aldeia e posterior liberação dos índios conforme o quadro a seguir: 


\begin{tabular}{cc}
\hline Ano & Indios da Aldeia \\
\hline 1762 & 3.500 \\
1770 & 2.619 \\
1779 & 2.563 \\
1784 & 1.362 \\
1814 & 300 \\
\hline
\end{tabular}

A destruição do espaço indígena continuou, em 1781, o engenho, a olaria e o potreiro de gado, que pertenciam à Caixa dos Índios, foram arrematados pela Irmandade do Santíssimo Sacramento. Em 1783, a Estância dos Povos e o açougue foram arrendados por 6 anos. No início do século passado, o rei doou a estância ao intendente de polícia Paulo Fernandes, com 10.000 cabeças de gado. A portaria de 18.11.1796 concedeu licença a Antônio Soares de Paiva para retirar da Aldeia dos Anjos os índios que fossem necessários para sua charqueada. Em 1.4.1800 encerraram as atividades no Recolhimento das Meninas, no ano seguinte o prédio do Colégio dos Meninos.

Finalmente, em 1803, os índios foram liberados para irem aonde quisessem, pois a Junta da Real Fazenda, em Porto Alegre, terminou com a administração da Aldeia dos Anjos.

\section{4 - O ESPAÇO PORTUGUÊS}

O espaço português, mapa 1 , iniciou com a ocupação dos Campos de Viamão, a partir de 1725 , por antigos tropeiros, que extraíam o gado da Vacaria do Mar. O litoral sul foi conquistado a partir de 1737, com a Comandância do Rio Grande, por famílias de soldados e casais de número. A extração de gado das estâncias missioneiras atraiu uma população que se fixa em frentes pioneiras na linha de fronteira.

A execução do Tratado de Madrid possibilitou a conquista da margem esquerda do Jacuí e os Campos de Cima da Serra. A retirada dos índios dos Sete Povos não era para povoar os Campos de Viamão, que desde 1736 já estavam ocupados do rio Mampituba ao Guaíba. A única intenção na transmigração dos índios para a Aldeia dos Anjos era de diminuir o potencial bélico dos espanhóis, que se apoiavam em grande parte nas milícias guaranis.

Mesmo com a conquista das terras ao sul do rio Jacuí, distribuídas por Joaquim Gonçalves da Silva, pai de Bento Gonçalves da Silva, aos seus soldados, parentes e amigos, não houve espaço para os guaranis. A conquista das 
Missões, em 1801, tomou terras dos índios dos Sete Povos, que foram distribuídas em forma de sesmarias entre os conquistadores e gente que veio dos Campos de Curitiba.

Apenas durante o breve governo de José Marcelino de Figueiredo, de 1769 a 1680, houve preocupação em organizar a administração da aldeia e de casar as índias com brancos.

A organização do espaço português, em suas dimensões geográfica, social e temporal, excluiu o índio. Nota-se uma preocupação de organização social nos editais sobre distribuição de terras.

O edital de 8.9.1764, de José Custódio de Sá e Faria, dispõe sobre a medição e marcação de terras. $\mathrm{O}$ do ano de 1765 , dispõe sobre os gaudérios, índios e brancos que perambulam pelos campos, para fixá-los nas vilas, como meio de civilizá-los.

O edital de 1769, de José Marcelino de Figueiredo, determina que os vagos e índios sejam colocados na organização social das vilas. $\mathrm{O}$ edital de 1773 dispõe sobre a distribuição de terras nos Campos de Cima da Serra, dando preferência ao branco casado com índia. $\mathrm{O}$ estancieiro era obrigado a povoar os campos com gado, pagando anualmente 1 cavalo manso por $1 / 2$ légua de campo; a plantar 4 laranjeiras, 4 amoreiras, 4 pessegueiros e 4 figueiras, proibindo que acolhesse desertores e índios em suas terras.

A aldeia de Nossa Senhora dos Anjos foi útil ao governo português, enquanto era necessário retirar os índios do lado espanhol, para que não produzissem e nem servissem de milicianos. A tentativa de Marcelino de Figueiredo, organizando social e economicamente os guaranis, durou apenas no período de seu governo.

\section{NOTAS}

1. Documento 8-2-25, Coleção de Angelis, Biblioteca Nacional.

2. PORTO, Aurélio. História das Missões Orientais do Uruguai, II vol., Porto Alegre, Selbach, 1954, p. 27-241.

3. ESCANDÓN, Juan de. História da Transmigração dos Sete Povos Orientais. . São Leopoldo, Inst. Anchietano de Pesquisas, 1983, p. 332-8.

4. ESCANDÓN, Juan de. Idem, p. 349.

5. ESCANDÓN, Juan de. Idem, p. 350.

6. Documento I-29-5-5, Coleção de Angelis, Biblioteca Nacional.

7. Documento I-29-5-18, Coleção de Angelis, Biblioteca Nacional.

8. NEIS, Ruben. A aldeia de Nossa Senhora dos Anjos, in Gravatai: História e Cultura, 1987 , p. 70-99.

9. Livro de Matrícula dos Indios da Aldeia de Nossa Senhora dos Anjos, caixa 32, vol. 328, Arquivo Histórico do RS. 


\section{BIBLIOGRAFIA COMPLEMENTAR}

CARDIEL, José. Compendio de la historia del Paraguay. Buenos Aires, FECIC, 1984. ESCANDÓN, Juan de. História da Transmigração dos Sete Povos Orientais. São Leopoldo, Instituto Anchietano de Pesquisas, 1983.

FLORES, Moacyr. Colonialismo e Missões Jesuiticas. Porto Alegre, EST, 1983.

MONTEIRO, Jonathas da Costa Rego. A Colonia do Sacramento. Porto Alegre, Globo, 1937.

NEIS, Ruben. Guarda Velha de Viamão. Porto Alegre, EST/Sulina, 1975.

PORTO, Aurélio. História das Missões Orientais do Uruguai. Porto Alegre, Selbach, 1954.

RÜDIGER, Sebalt. Colonização e propriedade de terras no Rio Grande do Sul. Porto Alegre, IEL, 1965.

VIANA, Hélio. História Diplomática do Brasil. Rio de Janeiro, Biblioteca do Exército, 1958. 
A transmigração dos guaranis para $a . .$.

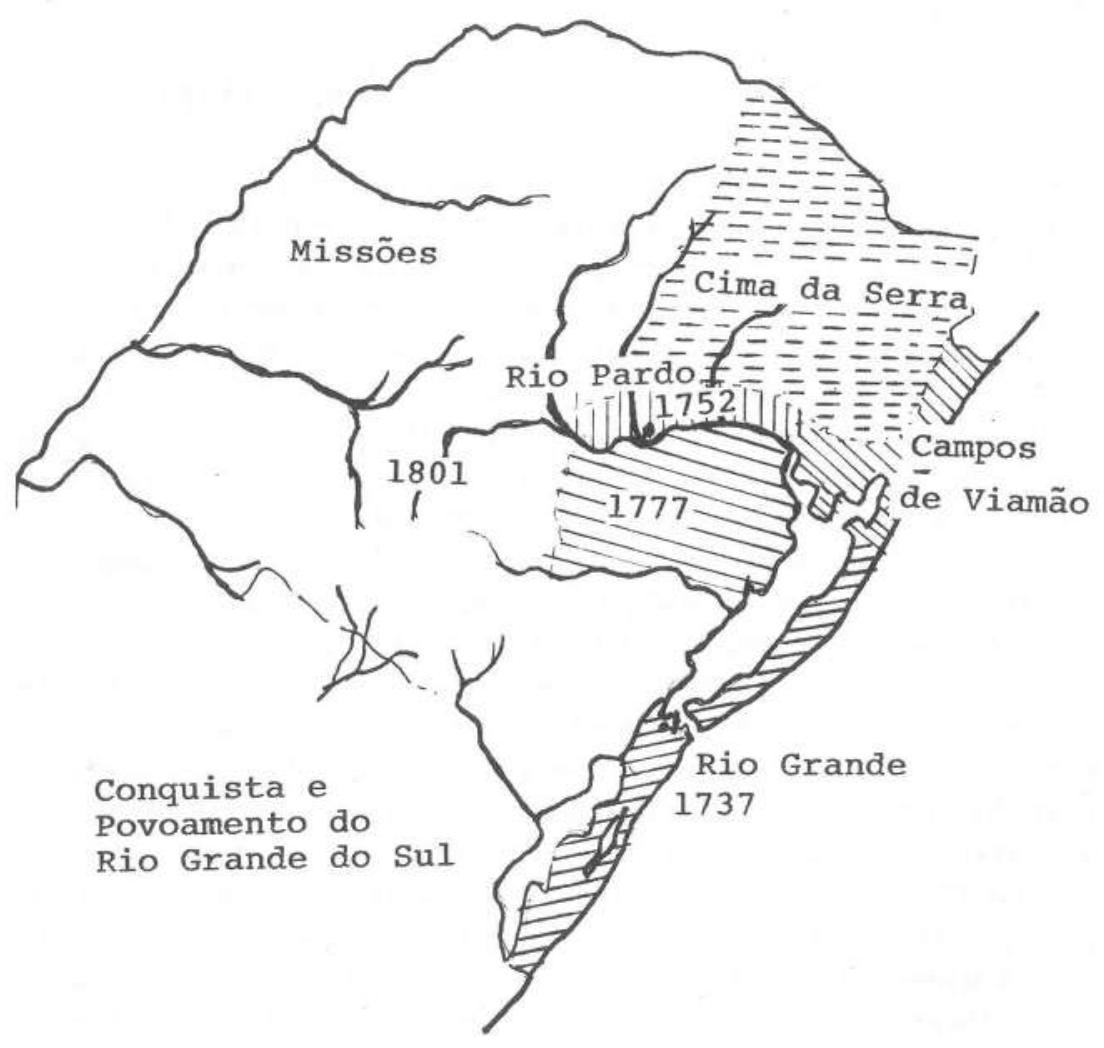

